\title{
The Moderating Effect of Hardiness on the Relationships between Problem-Solving Skills and Perceived Stress with Suicidal Ideation in Nursing Students
}

\author{
Abbas Abdollahi, Simin Hosseinian, \\ Elham Zamanshoar \\ Faculty of Educational Sciences and Psychol- \\ ogy, Alzahra University, Tehran, Iran \\ Ahmad Beh-Pajooh \\ Faculty of Psychology \& Education, \\ University of Tehran, Iran \\ Per Carlbring \\ Department of Psychology, Stockholm University, Sweden
}

\begin{abstract}
Recent evidence indicates an elevated risk of suicidal ideation for undergraduate nursing students. This research was designed to enhance the understanding of suicidal ideation in nursing students by investigating the relationships between problem-solving skills, perceived stress, hardiness, and suicidal ideation, with the possibility of hardiness acting as a moderator in the relationships between problem-solving skills appraisal and perceived stress with suicidal ideation. A multi-stage cluster random sample of Malaysian nursing undergraduate students $(\mathrm{N}=$ 204) completed self-report questionnaires. The results of structural equation modeling revealed that poor problem-solving skills, greater levels of perceived stress, and low levels of hardiness predicted greater levels of suicidal ideation. Also, hardiness emerged as a moderator in the links between problem-solving skills appraisal and perceived stress with suicidal ideation. The findings incrementally improve our understanding about the importance of hardiness as a moderator in explaining how problem-solving skills and perceived stress affect suicidal ideation. The results of this study are obtained from Malaysian nursing students and possible generalization to other populations should be verified by further studies.
\end{abstract}

Key words: problem-solving skills appraisal, perceived stress, hardiness, suicidal ideation

Suicide has become a serious and negative occurrence throughout the world, and it has been identified as the second leading cause of death in the individuals aged 15 to 25 years old (World Health Organization, 2012). Research findings have shown that the prevalence of suicide in nurses is higher than other medical occupations (Hawton, Agerbo, Simkin, Platt, \&

Correspondence concerning this article should be addressed to Simin Hosseinian, Department of Counseling, Faculty of Educational Sciences and Psychology, Alzahra University, Tehran, Iran. E-mail: Hosseinian@alzahra.ac.ir

Received September 6, 2017
Mellanby, 2011). One possible explanation for the higher suicide risk in nurses, compared with other medical occupations, is that their working conditions and the nature of the job make them vulnerable to burnout, anxiety, depression, and suicidal ideation (Leal \& Santos, 2015). Also, nursing students may be at greater suicide risk than other university students because in addition to theoretically based class sessions, they are also exposed to stressful clinical attachment. Hence, there is a need to learn to cope with suffering and death (Pulido-Martos, Augusto-Landa, \& Lopez-Zafra, 2012). This highlights the idea that undergraduate nursing students are at higher suicide risk than other 
university students. Therefore, it is important to understand suicidal ideation in nursing students when planning prevention programs to acquire better outcomes.

Maniam et al. (2014) revealed that Malaysian young adults had the highest risk for suicidal behavior compared to other age groups. There are series of significant cognitive shifts, physiological changes, and emotional changes that place young adults at risk for suicidal ideation (Maddi, 1989). The period of young adulthood is a period of rapid reorganization in all developmental aspects, and the effects of these developmental changes may influence young adults when making reasonable decisions concerning stressful life conditions, and such characteristics may contribute to their suicidal ideation (Wagner, 2012). Given such characteristics during this period, ineffective problem-solving skills may contribute to their self-destructive behavior.

Problem-solving skills have been shown to play a central role in the mental health of nursing students (Abdollahi, Talib, Yaacob, \& Ismail, 2014; Campos et al., 2016). Heppner and colleagues (2004) highlighted the role of poor problem-solving skills in clarifying psychological disorders, such as depression and suicide. They coined the term problem-solving skills appraisal, and have defined it as one's capacity and skill to deal with problems throughout his/ her life. The authors identified three styles of problem-solving skills: problem-solving confidence, approach-avoidance style, and personal control. Problem-solving confidence is defined as an estimation of one's opinion about one's own capacity to achieve goals and what is necessary to reach the final goal (Heppner et al., 2004). In their work, the authors explained that some individuals could not make a decision when encountering problems, and they might withdraw from forthright confrontation, preferring to avoid their problems, or they might prefer straight confrontation of their problems and provide responses to the problems (approachavoidance style). The third style is personal control, which is similar to the theoretical conceptualization of control created by Rotter (1966). Heppner and colleagues (2004) explained that when individuals encounter problems, they may perceive that they have abilities to control their emotional responses during the stressful situations (personal control). Numerous studies have suggested that ineffective problemsolving skills serve as a significant correlate of suicidal ideation (Abdollahi, Talib, Yaacob, \& Ismail, 2015a, 2015b). However, to the best of our knowledge, no study has investigated the relationship between problem-solving skills and suicidal ideation among Malaysian nursing students.

Stress has been considered a hindrance to concentration, problem-solving skills, and mental health in nursing students (Reeve, Shumaker, Yearwood, Crowell, \& Riley, 2012). Sources of stress affecting nursing students, such as economic problems, frequent examinations, increased separation from family, adjusting to an new academic environment and culture as well as perceived pressures for academic achievement and increased workloads are commonly reported sources of nursing student stress (Jameson, 2014). Such demands create a stressful developmental period for nursing students, which may be harmful to them. In the present study, perceived stress was the degree to which a circumstance in one's life is estimated to be stressful (Cohen, 1996). Previous studies also revealed that nursing students experienced high levels of stress (Abdollahi, Abu Talib, Yaacob, \& Ismail, 2014). According to Lazarus and Folkman's (1984) cognitive-transactional stress theory, appraisal and interpretation of the event is more important than the event itself. Several studies have found a direct relationship between stress and suicidal ideation among nurses (Aradilla-Herrero, Tomás-Sábado, \& Gómez-Benito, 2014; Wang, Lai, Hsu, \& Hsu, 
2011); however, the relationship between stress and suicidal ideation among Malaysian nursing student has not been investigated.

According to Maddi and colleagues (2012), psychological hardiness as a secondary appraisal is composed of three interacting attitudes, labeled as follows: challenge - an attitude that continuing to learn from experience is more fulfilling than expecting comfort and security; control - an attitude that the struggle to influence outcomes is more advantageous than passivity and powerlessness; and commitment - an attitude that involvement is more advantageous than detachment. Maddi (2006) believes that hardiness enables individuals to feel committed, to have a greater sense of emotional control under stressful situation.

There is still a gap in the literature according to a great deal of evidence of the associations between poor problem-solving skills appraisal and perceived stress with suicidal ideation. It is unclear why some individuals with effective problem-solving skills and low levels of perceived stress experience greater amounts of suicidal ideation. There are two reasons to support the moderating role of hardiness: individuals with poor problem-solving skills are less likely to think of suicide, because hardiness enables them to handle their emotions, allows for commitment to fruitful social activities, challenges them with their stressful conditions, and provides flexibility by turning negative conditions into opportunities to grow and gain wisdom (Maddi, 2006). Hardy individuals are also less likely to evaluate stressful circumstances as frightening and unmanageable, and they appraise stressful situations as a challenge for acquiring new experiences even under stressful conditions. Therefore, they are less likely to suffer from suicidal thoughts (Abdollahi, Talib, Yaacob, \& Ismail, 2015c; Jameson, 2014). Most prior studies have generally investigated linear associations between problem-solving skills and perceived stress with suicidal ideation in nursing students (Leal \& Santos, 2015), but have neglected the possible moderating influence of hardiness on these associations. Therefore, the precise mechanism that accounts for problem-solving skills and perceived stress with suicidal ideation remains to be delineated. Consequently, this study is designed to examine the possible moderating effect of hardiness in the links between problem-solving skills appraisal and perceived stress in relation to suicidal ideation among Malaysian nursing undergraduates.

Therefore, the present study hypothesized as follows: 1) poor problem-solving skills and high levels of perceived stress will positively predict suicidal ideation, and 2) hardiness will moderate the links between problem-solving skills appraisal and perceived stress with suicidal ideation among nursing students.

\section{Method}

\section{Participants}

A total of 214 nursing students were recruited via a multi-stage cluster sampling approach to participate in the study. Of these, four cases were omitted from the analysis due to incomplete information and 6 cases were removed from the analysis due to outlier values. Finally, 204 nursing students were involved in the present analysis.

\section{Procedure}

Ethical endorsement was granted by the Ethical Research Committee of University Putra Malaysia (UPM) before research beginning. Before collecting data, permission to conduct research among nursing students was obtained from the universities involved. In the first stage, from the four public universities in Selangor state, two universities were selected randomly (Universiti Putra Malaysia and Universiti 
Kebangsaan Malaysia). In the next stage, a class from each nursing school according to the students' grade year (freshman, sophomore, junior, and senior) was randomly selected, and data were collected during one of the regularly scheduled classes. Data were collected from January 13, 2014 to April 15, 2014. All the participants were informed regarding the research goals, and signed the consent form. They were also guaranteed confidentiality and their rights to withdraw from the study at any time. The respondents completed the self-reported questionnaires.

\section{Measures}

The 32-item Problem-Solving Inventory (PSI) (Heppner, 1988) was used to assess one's capacity and skill to deal with hardships in one's daily life (Heppner, 1988). A 6-point Likert scale was used for all questions. This measure consists of three factors, as follows: Problem-Solving Confidence (PSC), Approach-Avoidance Style (AAS), and Personal Control (PC). Heppner (1988) suggests that the factors are dependent; therefore, in this study, the sum of three factors was used. A lower score in PSI shows effective problem-solving skills. Previous studies revealed that PSI had good validity and acceptable internal consistency, with $\alpha=$ 0.80 (Heppner, 1988; Heppner et al., 2004).

The 10-item Perceived Stress Scale (Cohen, Kamarck, \& Mermelstein, 1983) was used to assess the degree of stressful circumstances and measure the opinions of nursing students about how circumstances are unpredictable, uncontrollable, and excessive. A 4-point Likert scale was used for all questions, with total scores ranging from 0 to 40 . A higher score indicates higher levels of perceived stress. Cohen (1996) reported perceived stress scale had a good internal consistency, with $\alpha=0.84$.

The 18-item Personal Views Survey II (Maddi et al., 2006) was used to assess one's ability and skill to handle stressful life events. Each item was rated on a 4-point Likert scale, ranging from 0 (not at all true) to 3 (very true). The sum of these three components indicates degree of hardiness (Maddi, 2006). The total score range is from 0 to 54 . A higher score indicates greater hardiness. The study showed an acceptable internal consistency (Maddi et al., 2006). The hardiness literature supports the sum of the subscales of the hardiness components - commitment, control, and challenge (Cole, Feild, \& Harris, 2004; Maddi, 2006). Thus, the sum of three scores was utilized in this study.

The 21-item Beck Scale for Suicidal Ideation (BSSI) (Beck, Steer, \& Ranieri, 1988) was used to measure suicidal ideation, planning, and intent to commit suicide in the past week. Each item was rated on a 3-point Likert scale from 0 to 2 for all questions, with total scores ranging from 0 to 38 (Beck et al., 1988). A high BSSI score means that the respondent is at higher risk of suicide. The study confirmed concurrent validity between individuals with a high BSSI score and experience of suicide attempts (Beck et al., 1988).

Demographic information was collected to measure different features of the nursing students' backgrounds. Respondents completed a demographic survey about their gender, race, age, educational level, and marital status.

\section{Results of Pilot Study}

The questionnaires were pilot tested by convenience sampling, in which 30 nursing students were chosen. Cronbach's alpha was used for evaluating the reliability of the questionnaires (English version). The Problem-Solving Inventory had a Cronbach's alpha value of $\alpha=0.86$, the Perceived Stress Scale had a Cronbach's Alpha value of $\alpha=0.81$, the Hardiness Scale had a Cronbach's alpha value of $\alpha=0.78$, and the Beck Suicidal Ideation Scale had a Cronbach's alpha value of $\alpha=0.90$. Therefore, 
the reliability coefficients showed that all the questionnaires were stable and consistent.

\section{Data Analysis and Data Preparation}

Structural Equation Modeling (SEM), using AMOS version 23 (Analysis of Moment Structures), and SPSS version 23 (Statistical Package for the Social Sciences) were employed to analyze the data.

In the process of data screening, the missing data, outliers, and normality of distribution were checked and addressed. Missing data were addressed using the regression imputation method. Outliers were checked by high Mahalanobis $d$-squared with both $p 1$ and $p 2$ equal .000 and $.000 ; 6$ cases were found as outliers, and these cases were deleted. For all variables, skewness values ranged from 0.003 to 0.598 , and kurtosis values ranged from -1.038 to 1.625 ; on that basis, the distribution was considered normal [As a rule of thumb, Byrne (2010) described that when skewness and kurtosis values are lower than \pm 3 and \pm 5 , respectively, data are appropriate to assume normality].

According to Kline's (2010) recommendation, the following 6 indices were employed to assess the measurement model fit: the chi square/ degree of freedom ratio (CMIN/DF), the Goodness-of Fit Index (GFI), the Comparative Fit Index (CFI), the Tucker-Lewis Index (TLI), and the Incremental Fit Index (IFI). A rule of thumb for the fit indices is that values equal or greater than .90 are an acceptable fit (Kline, 2010). Fur- thermore, the model may be classified as acceptable, if the Root Mean Squared Error of Approximation (RMSEA) is between .03 and .08 .

\section{Results}

\section{Respondent Profile}

The age range of the respondents was from 18 to 24 years old $($ mean age $=21.51, S D=3.21)$. The sample consisted of 98 (48\%) males and $106(52 \%)$ females, and the majority of respondents $(86.4 \%, n=177)$ were single. Nearly half of the respondents were Malay $(48 \%, n=98)$, followed by Chinese $(41 \%, n=83)$, and Indian $(11 \%, n=22)$. Of the 204 nursing students, $30.2 \%$ $(n=61)$ were in their freshman year; $22.8 \%(n=$ 47) were in their sophomore year; $25.6 \%(n=$ $52)$ were in their junior year, and $21.4 \%(n=44)$ were in their senior year.

\section{Convergent Validity and Construct Reliabil- ity of the Instruments}

The convergent validity (Average Variance Extracted; AVE) and construct reliability (Construct Reliability; CR) of the instruments (English version) were assessed in the main study. The establishment of convergent validity and construct reliability are confirmed if AVE and $\mathrm{CR}$ are above the recommended standard values of .50 and .70, respectively (Byrne, 2010). As seen in Table 1, the values of AVE and $\mathrm{CR}$ showed good internal consistency values

Table 1 Values of Average Variance Extracted (AVE) and Construct Reliability (CR)

\begin{tabular}{lcc}
\hline Measure & AVA & CR \\
\hline Problem-Solving Inventory & .71 & .86 \\
Perceived Stress Scale & .62 & .76 \\
Personal Views Survey & .59 & .73 \\
Beck Scale for Suicidal Ideation & .79 & .85 \\
\hline
\end{tabular}

Note. AVE: Average Variance Extracted and CR: Construct Reliability 
and convergent validity values for the instruments.

\section{Descriptive Statistic}

Table 2 shows the mean, standard deviation, actual range, and inter-correlations of the studied variables. Table 2 shows that poor problemsolving skills $(r=69, p<.01)$ and perceived stress $(r=53, p<.01)$ were positively correlated with suicidal ideation, whereas hardiness $(r=-.57$, $p<.01$ ) was negatively correlated with suicidal ideation. Additionally, hardiness was negatively correlated with perceived stress $(r=-.69, p<.01)$ and problem-solving skills $(r=-.63, p<.01)$.

\section{Measurement Model of Study}

The results showed that the measurement model fit the data well: $\mathrm{CMIN} / \mathrm{DF}=1.78, p<.05$, $\mathrm{GFI}=.91, \mathrm{CFI}=.92, \mathrm{TLI}=.94, \mathrm{IFI}=.90$, and RMSEA $=.04$. Although the model based on significant chi-square values did not fit the data, other indices depicted good fit indices. Therefore, according to Kline (2010), the measurement model fitted the data perfectly.

\section{Structural Model}

The results, as demonstrated in Figure 1, indicated that poor problem-solving skills appraisal $(\beta=.42, p<.01)$, high levels of perceived stress $(\beta=.31, p<.01)$, and low levels of hardiness $(\beta=-.32, p<.01)$ had significant contributions in prediction of suicidal ideation. These exogenous variables explain $71.0 \%$ of the variance in suicidal ideation.

\section{Moderation Test of Hardiness}

To investigate the moderating role of hardiness on the associations between problem-solving skills and perceived stress with suicidal ideation, multi-group analysis in AMOS (Version 23) was performed. The first step in examining the moderating role of hardiness on the associations of problem-solving skills, perceived stress, and suicidal ideation is to compare the unconstrained model (paths free to vary) versus the constrained model (paths constrained to equality). If the unconstrained model is better than the constrained model, we can conclude that hardiness has a moderation effect on the overall model. The next step in examining the moderating role of hardiness is to check for the significance of individual paths. The path is moderated by the moderating variable if 1) the beta for one group is significant, while the beta value for another group is not significant, or 2) the beta values for all groups are significant, but the correlation coefficient for the association between two variables for one group is positive and for another group is negative (Kline, 2010).

Table 2 Correlation among study variables, and the mean, standard deviations, and observed range

\begin{tabular}{lcccc}
\hline Variables & -1 & -2 & -3 & -4 \\
\hline (1) Suicidal Ideation & 1 & & & \\
(2) Perceived Stress & $.53^{* *}$ & 1 & & \\
(3) Hardiness & $-.57^{* *}$ & $-.69^{* *}$ & 1 & \\
(4) Problem-Solving Skills Appraisal & $.69^{* *}$ & $.62^{* *}$ & $-.63 * *$ & 1 \\
Mean & 5.43 & 17.34 & 29.71 & 81.68 \\
Standard deviation & 4.02 & 8.79 & 12.42 & 21.59 \\
Observed range & $0-27$ & $4-36$ & $10-54$ & $32-154$ \\
\hline
\end{tabular}

Note. $* * p<.01$. 


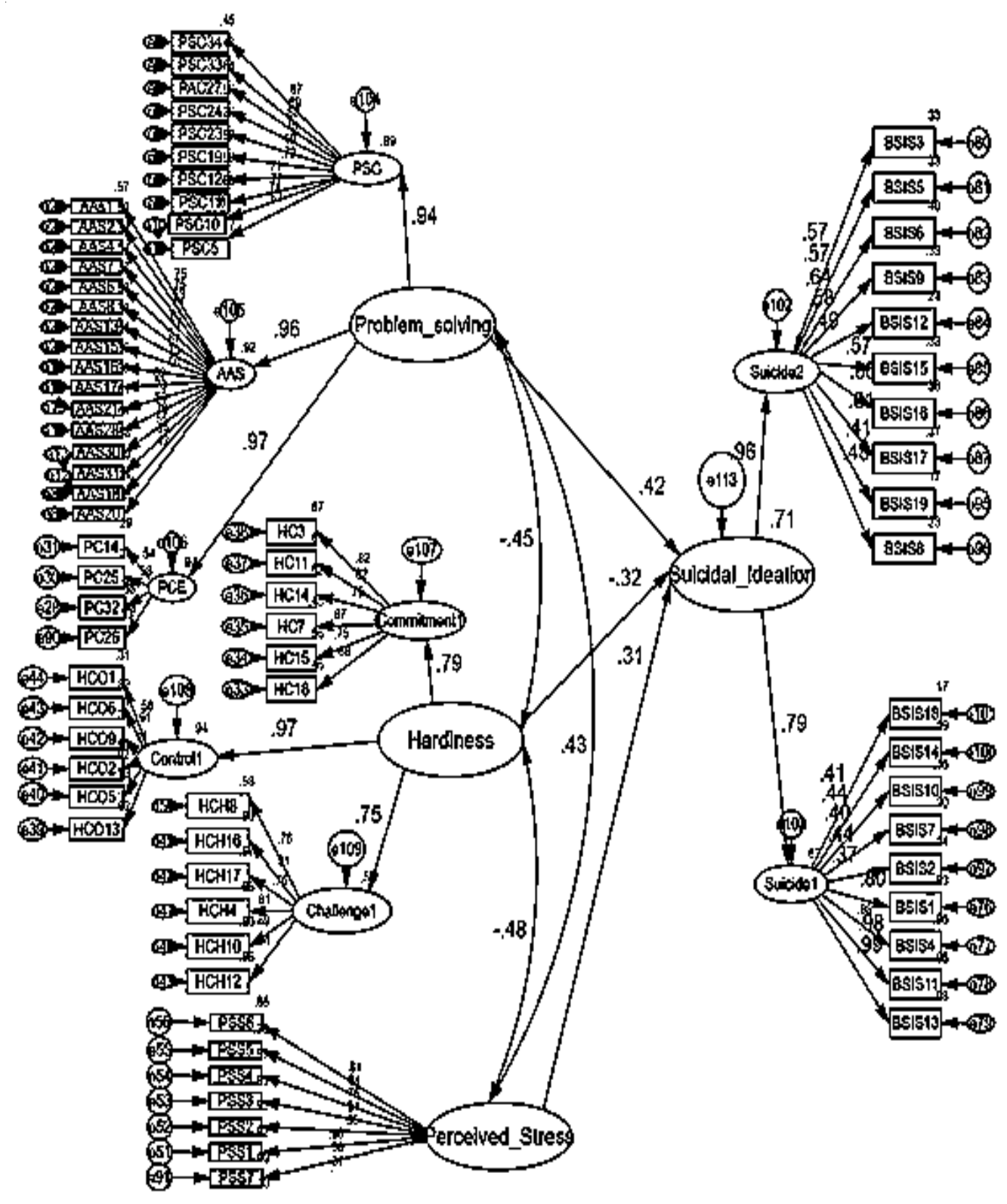

Figure 1 Structural model of suicidal ideation 
Table 3 Standardized regression weights (hardiness variant model)

\begin{tabular}{|c|c|c|c|c|}
\hline \multirow{2}{*}{ Hypothesis } & & & \multicolumn{2}{|c|}{ Hardiness } \\
\hline & & & Std Est & $\mathrm{CR}(\mathrm{SE})$ \\
\hline Suicidal ideation & $<---$ & $\begin{array}{l}\text { Perceived } \\
\text { stress }\end{array}$ & $-.312 * *(.077)$ & $-1.843(.653)$ \\
\hline Suicidal ideation & $<---$ & $\begin{array}{l}\text { Problem- } \\
\text { solving skills }\end{array}$ & $.224 *(.096)$ & $.987(.704)$ \\
\hline
\end{tabular}

Note. $\mathrm{SE}=$ standard error, $\mathrm{CR}=$ critical ratio, $\mathrm{Std}$ Est $=$ standard estimate.

Result for the low hardiness group is presented first, and results for the high hardiness group is presented in parenthesis.

$* p<.05, * * p<.01$

To test the moderating role of hardiness, the sample data were divided into high and low groups based on the median split in hardiness (29.71). The measurement fit indices for the unconstrained model $\left(\chi^{2}=4.212, p<0.001\right.$, $\mathrm{RMSEA}=.041, \mathrm{CFI}=.911, \mathrm{GFI}=.933, \mathrm{NFI}=$ .921) were better than the measurement fit indices for the constrained model $\left(\chi^{2}=5.133 p<\right.$ 0.001 , RMSEA $=.065, \mathrm{CFI}=.897, \mathrm{GFI}=.880$, $\mathrm{NFI}=.833$ ), because the chi-square value for the unconstrained model was smaller than the chi-square value for the constrained model, and other fit indices for the unconstrained model were greater than the measurement fit indices of the constrained model (Kline, 2010). Therefore, there is a considerable difference in the influence of hardiness on the relationships between problem-solving skills and perceived stress with suicidal ideation.

The result, as demonstrated in Table 3, revealed that hardiness moderated the association of perceived stress and suicidal ideation; that is, the nursing students from the high hardiness group were less likely to experience suicidal ideation, regardless of their perceived stress. The moderating role of hardiness on the link between problem-solving skills and suicidal ideation was also supported; specifically, nursing students with high levels of hardiness were less likely to experience suicidal ideation, re- gardless of their ineffective problem-solving skills.

\section{Discussion}

The first hypothesis of the present study involved examining the relationships between problem-solving skills and perceived stress with suicidal ideation among nursing students. As anticipated, our findings provide support for positive associations between poor problem-solving skills and high levels of perceived stress with suicidal ideation. One possible explanation for the positive association between poor problem-solving skills and suicidal ideation is that individuals, who tend to use less effective problem-solving skills are more likely to engage in withdrawal, decreased assertiveness, sadness, irritability, and passivity that contribute to the risk for suicidal ideation. On the other hand, individuals with effective problem-solving skills are able to regulate their own emotions and neutralize negative thoughts, and are less likely to suffer from suicidal ideation (Abdollahi et al., 2015b; Khan, Hamdan, Ahmad, Mustaffa, \& Mahalle, 2016; Siu, 2009). This finding is consistent with previous studies (BeckerWeidman et al., 2010) that found that ineffective problem-solving skills have a great influence on increased suicidality. This idea ema- 
nates from studies that have demonstrated that effective problem-solving skills reduced the risk of suicidal ideation (Speckens \& Hawton, 2005). Given the chemical, physical, and psychological changes during puberty (Heim \& Binder, 2012), undergraduate students need to find a new role in society and take decisions about academic, occupational, and marital affairs, which affect their future and their identities. Therefore, these demands mean that problemsolving skills are necessary for them, because they need to find logical solutions for their problems; otherwise, they may be suffering from suicidal ideation (Becker-Weidman et al., 2010).

This finding also showed that perceived stress positively predicted suicidal ideation among nursing students. This finding is in agreement with Abdollahi and colleagues (2015c), who found that stress was positively correlated with suicidal ideation. Suicidal behavior is an outcome of perceived stress, meaning that one cannot bear the stressful conditions and thinks that suicide is the best solution for escaping an unbearable situation. According to the cognitivetransactional stress theory (Lazarus \& Folkman, 1984), perceived stress is produced by the perception of stressful situations and estimation of one's own ability to manage the stressors in which the effects on the individuals are more than that of the real stressors. This theory suggests that there are diversities in everyone's reaction to the same potential stressors, and these differences influence both the level of appraisal and the ability to solve problems.

The second hypothesis of this study involved examining the moderating role of hardiness on the links between problem-solving skills and perceived stress with suicidal ideation among nursing students. The present findings showed that hardiness moderated the link between problem-solving skills appraisal and suicidal ideation. That is, nursing students with high levels of hardiness are more likely to apply hardy attitudes and courage to confront problems, and they are more flexible in facing problems. The hardiness theory (Maddi, 2006) displays two types of appraisals in relation to suicidality. First, the situation is assessed by problem-solving skills as a primary appraisal. Second, hardiness as a secondary appraisal plays an important role in the relationship between problemsolving skills and suicidal ideation. This means that when the situation is assessed as a threatening and uncontrollable situation, the likelihood of suicidal ideation increased. However, when the situation is assessed as a challengeable or opportunity for learning, hardiness acts as an obstacle to engaging in suicidal ideation, meaning that hardy individuals were less likely to experience suicidal ideation even at the highest levels of ineffective problem-solving skills. The findings of this study support previous research showing that positive secondary appraisals may reduce the risk of suicidal ideation (Johnson, Gooding, Wood, \& Tarrier, 2010), proving that hardiness is an important element in completing tasks and adapting to challenging situations.

The findings also revealed that hardiness acted as a significant moderator in the link between perceived stress and suicidal ideation. The findings showed that one of the influencing factors against stress is hardiness and that nursing students with strong hardiness, even those having high levels of perceived stress, were less likely to experience suicidal ideation. The findings further confirm the theorists' claims by explaining that hardiness provides courage, motivation, and effective coping strategies to enhance performance and mental health under stressful circumstances (Maddi, 2006). Hardy attitudes help individuals to have healthy life by looking for effective solutions for their daily problems and providing persevering attitude to view stressful circumstances as less stressful and more challengeable and controllable (Abdollahi et al., 2016). The findings of this study emphasize the important role of har- 
diness as an enhancing factor in decreasing the amount of perceived stress and suicidal ideation. Hardiness appears as a general orientation towards self, and the world conceptualized as comprising of a sense of commitment, control, and challenge. Particularly, individuals with strong hardiness are committed to what they do in diverse aspects of their lives; believe in having some control over the causes and solutions of problems, and view life changes and adjustment demands as challenges and opportunities. Therefore, hardy individuals tend to remain strong during hardship, and these characteristics appear to protect them against feeling of hopelessness

\section{Implications for Practice}

The current study contributes to the existing knowledge on suicidal ideation among nursing students in the Malaysian context, where research on suicidal ideation in Malaysia is limited. Theoretically, the findings of this study fill the gap in the suicidal research carried out in Malaysia and add to the existing literature on understanding hardiness as an influencing and enhancing factor for nursing students against suicidal ideation. Thus, the current study contributes valuable information through developing the credibility of hardiness theory and supports the portability of this theory to a Malaysian nursing student sample. Methodologically, this study adopts a more sophisticated statistical procedure in using structural equation modeling. This analysis takes one step closer to a better understanding of the hypothesized model of suicidal ideation in contrast to conventional linear regression. Using structural equation modeling and multi-group analysis provide further insight into the relationship between the studied variables. Therapeutically, clarifying the relationships between problem-solving skills appraisal, perceived stress, and hardiness with suicidal ideation among nursing students can assist in the creation of effective prevention and intervention programs to reduce suicidal ideation. For example, when practitioners or psychologists evaluate the risk of suicide in nursing students, they need to assess the amount of perceived stress, problem-solving skills, and hardiness. Although causality is unable to be determined in this study, hardiness training may decrease the likelihood of suicidal ideation.

\section{Strengths and Limitations}

The findings of the current study must be viewed in relation to its limitation. This study is restricted to nursing students in Selangor state, and possible generalization to other populations should be verified by further studies. This study utilized self-report questionnaires. Even though the questionnaires used in this research are psychometrically qualified, self-report questionnaires pose a threat to the internal validity of the data. Therefore, future studies should use a multi-method approach, including quantitative and qualitative methods that provide incremental validity to the data. As the present study was a cross-sectional survey, it constrained us to a discussion about the associations between variables rather than causality. It is necessary to replicate this study with longitudinal and experimental designs to examine the process through which the problem-solving skills, hardiness, and perceived stress affect suicidal ideation.

\section{References}

Abdollahi, A., Talib, M. A., Yaacob, S. N., \& Ismail, Z. (2014). Hardiness as a mediator between perceived stress and happiness in nurses. Journal of Psychiatric and Mental Health Nursing, 21(9), 789-796. http://doi.org/10.1111/jpm.12142

Abdollahi, A., Talib, M. A., Carlbring, P., Harvey, R., Yaacob, S. N., \& Ismail, Z. (2016). Problem-solving skills and perceived stress among undergraduate stu- 
dents: The moderating role of hardiness. Journal of Health Psychology, https://doi.org/10.1177/ 1359105316653265.

Abdollahi, A., Talib, M. A., Yaacob, S. N., \& Ismail, Z. (2014). Problem-solving skills and hardiness as protective factors against stress in Iranian nurses. Is sues in Mental Health Nursing, 35(2), 100-107. http://doi.org/10.3109/01612840.2013.843621

Abdollahi, A., Talib, M. A., Yaacob, S. N., \& Ismail, Z. (2015a). Problem-solving skills and suicidal ideation among Malaysian college students: The mediating role of hopelessness. Academic Psychiatry, 43(2), 1-7. http://doi.org/1 0.1007/s40596-015-0383-0

Abdollahi, A., Talib, M. A., Yaacob, S. N., \& Ismail, Z. (2015b). Problem-solving skills appraisal mediates hardiness and suicidal ideation among Malaysian undergraduate students. Plos One, 10(4), 1-14. http:/ /doi.org/10.1371/journal.pone.0122222

Abdollahi, A., Talib, M. A., Yaacob, S. N., \& Ismail, Z. $(2015 \mathrm{c})$. The role of hardiness in decreasing stress and suicidal ideation in a sample of undergraduate students. Journal of Humanistic Psychology, 55(2), 202-222.

Aradilla-Herrero, A., Tomás-Sábado, J., \& GómezBenito, J. (2014). Associations between emotional intelligence, depression and suicide risk in nursing students. Nurse Education Today, 34(4), 520-525.

Beck, A. T., Steer, R. A., \& Ranieri, W. F. (1988). Scale for Suicide Ideation: Psychometric properties of a self-report version. Journal of Clinical Psychology, 44(4), 499-505. http://doi.org/10.1002/1097

Becker-Weidman, E. G., Jacobs, R. H., Reinecke, M. A., Silva, S. G., \& March, J. S. (2010). Social problem-solving among adolescents treated for depression. Behaviour Research and Therapy, 48(1), 1118

Byrne, B. M. (2010). Structural equation modeling with AMOS: Basic concepts, applications, and programming, second edition. (L. E. A. Publishers, Ed.) Routledge Academic. Retrieved from http:// www.amazon.com/dp/0805863737

Campos, R. C., Holden, R. R., Costa, F., Oliveira, A. R., Abreu, M., \& Fresca, N. (2016). The moderating effect of gender on the relationship between coping and suicide risk in a Portuguese community sample of adults. Journal of Mental Health, 26(1), 66-73. http://doi.org/10.1080/09638237.2016.1222066

Cohen, S. (1996). Psychological stress, immunity, and upper respiratory infections. Current Directions in Psychological Science, 5(3), 86-90. Retrieved from http://www.jstor.org/stable/20182399

Cohen, S., Kamarck, T., \& Mermelstein, R. (1983). A global measure of perceived stress. Journal of Health and Social Behavior, 24(4), 385-396. Retrieved from http://www.ncbi.nlm.nih.gov/pubmed/6668417
Cole, M. S., Feild, H. S., \& Harris, S. G. (2004). Student learning motivation and psychological hardiness: Interactive effects on students' reactions to a management class. Academy of Management Learning \& Education, 3(1), 64-85. http://doi.org/10.5465/ AMLE.2004.12436819

Hawton, K., Agerbo, E., Simkin, S., Platt, B., \& Mellanby, R. J. (2011). Risk of suicide in medical and related occupational groups: A national study based on Danish case population-based registers. Journal of Affective Disorders, 134(1), 320-326.

Heim, C., \& Binder, E. B. (2012). Current research trends in early life stress and depression: Review of human studies on sensitive periods, gene-environment interactions, and epigenetics. Experimental Neurology, 233(1), 102-111. http://doi.org/http:// dx.doi.org/10.1016/j.expneurol.2011.10.032

Heppner, P. P. (1988). The Problem Solving Inventory: Manual. Palo Alto, CA:Consulting Psychologists Press.

Heppner, P. P., Witty, T. E., \& Dixon, W. A. (2004) Problem-solving appraisal and human adjustment: A review of 20 years of research using the Problem Solving Inventory. The Counseling Psychologist, 32(3), 344-428.

Jameson, P. R. (2014). The effects of a hardiness educational intervention on hardiness and perceived stress of junior baccalaureate nursing students. Nurse Education Today, 34(4), 603-607. http://doi.org/ 10.1016/j.nedt.2013.06.019

Johnson, J., Gooding, P. A., Wood, A. M., \& Tarrier, N. (2010). Resilience as positive coping appraisals: Testing the Schematic Appraisals Model of Suicide (SAMS). Behaviour Research and Therapy, 48(3), 179-186.

Khan, A., Hamdan, A. R., Ahmad, R., Mustaffa, M. S., \& Mahalle, S. (2016). Problem-solving coping and social support as mediators of academic stress and suicidal ideation among Malaysian and Indian adolescents. Community Mental Health Journal, 52(2), 245-250.

Kline, R. B. (2010). Principles and practice of structural equation modeling. New York.The Guilford Press. Retrieved from http://books.google.com.my

Lazarus, R. S., \& Folkman, S. (1984). Stress, appraisal, and coping. New York, Springer Publishing Company.

Leal, S. C., \& Santos, J. C. (2015). Suicidal behaviors, social support and reasons for living among nursing students. Nurse Education Today, 36, 434-438. http:/ /doi.org/10.1016/j.nedt.2015.09.012

Maddi, S. R. (1989). Personality theories: A comparative analysis. New York, Dorsey Press.

Maddi, S. R. (2006). Hardiness: The courage to grow from stresses. The Journal of Positive Psychology, l(3), 160-168. 
Maddi, S. R., Harvey, R. H., Khoshaba, D. M., Fazel, M., \& Resurreccion, N. (2012). The relationship of hardiness and some other relevant variables to college performance. Journal of Humanistic Psychology, 52(2), 190-205. http://doi.org/10.1177/ 0022167811422497

Maddi, S. R., Harvey, R. H., Khoshaba, D. M., Lu, J. L., Persico, M., \& Brow, M. (2006). The personality construct of hardiness, III: Relationships with repression, innovativeness, authoritarianism, and performance. Journal of Personality, 74(2), 575-598. http://doi.org/10.1111/j.1467-6494.2006.00385.x

Pulido-Martos, M., Augusto-Landa, J. M., \& LopezZafra, E. (2012). Sources of stress in nursing students: A systematic review of quantitative studies. International Nursing Review, 59(1), 15-25.

Reeve, K. L., Shumaker, C. J., Yearwood, E. L., Crowell, N. A., \& Riley, J. B. (2012). Perceived stress and social support in undergraduate nursing students' educational experiences. Nurse Education Today, 33(4), 419-424. http://doi.org/http://dx.doi.org/10.1016/ j.nedt.2012.11.009
Rotter, J. B. (1966). Generalized expectancies for internal versus external control of reinforcement. Psychological Monographs: General and Applied, 80(1), 1-28. http://doi.org/10.1037/h0092976

Siu, A. F. Y. (2009). Trait emotional intelligence and its relationships with problem behavior in Hong Kong adolescents. Personality and Individual Differences, 47(6), 553-557.

Speckens, A. E. M., \& Hawton, K. (2005). Social problem solving in adolescents with suicidal behavior: A systematic review. Suicide and Life-Threatening Behavior, 35(4), 365-387.

Wagner, K. D. (2012). Suicidal behavior in children and adolescents. Psychiatric Times, 28(14), 24.

Wang, R.-H., Lai, H.-J., Hsu, H.-Y., \& Hsu, M.-T (2011). Risk and protective factors for suicidal ideation among Taiwanese adolescents. Nursing Research, 60(6), 413-421.

World Health Organization. (2012). Suicide prevention (SUPRE). Retrieved from http://www.who.int/ mental_health/prevention/suicide/suicideprevent/en/ index. $\bar{h}$ tml 